\title{
AUTHOR INDEX FOR VOLUME 99
}

ALLU, V., THOMAS, D. K. and TUNESKI, N.; On Ozaki close-to-convex functions

AMIRI, M. and ARIANNEJAD, M.; Finite unitary rings in which all Sylow subgroups of the group of units are cyclic

ARIANNEJAD, M.; see AMIRI, M.

ASSADI, A., FARZANEH, M. A. and MOHAMMADINEJAD, H. M.; On the decomposition of operators with several almost-invariant subspaces

BAJNOK, B. and MATZKE, R.; The maximum size of $(k, l)$-sum-free sets in cyclic groups

BALESTRO, V. and MARTINI, H.; The Rosenthal-Szasz inequality for normed planes

BASDOURI, I.; see ECHI, N.

BENALI, H.; see ECHI, N.

BHATIA, S.; Algebraic models of large scale genome rearrangement events

BIGELOW, S. and LEVAILLANT, C.; An exact entangling gate using Fibonacci anyons

BRESCIA, M. and RUSSO, A.; Groups satisfying the double chain condition on abelian subgroups

CABELLO SÁNCHEZ, J. and GORDILLO-MERINO, A.; A characterisation of Euclidean normed planes via bisectors

CESPEDES, M. I.; Detection of longitudinal brain atrophy patterns consistent with progression towards Alzheimer's disease

CHATTOPADHYAY, J., ROY, B., SARKAR, S. and THANGADURAI, R.; Quadratic nonresidues and nonprimitive roots satisfying a coprimality condition

CHEN, S.-Q., TANG, M. and YANG, Q.-H.; On a problem of Chen and Lev

CHEN, S. T. and GAO, Z.; An improved result on ground state solutions of quasilinear Schrödinger equations with super-linear nonlinearities

CHEN, Y.-G.; see MA, W.-X.

DONG, L.; Stochastic Navier-Stokes equations on 2D rotating spheres with stable Lévy noise

DUDEK, A. W., PAŃKOWSKI, Ł. and SCHARASCHKIN, V.; Note on the number of divisors of reducible quadratic polynomials

ECHI, N., BASDOURI, I. and BENALI, H.; A separation principle for the stabilisation of a class of fractional order time delay nonlinear systems

EDIE-MICHELL, C.; The classification of categories generated by an object of small dimension

FARZANEH, M. A.; see ASSADI, A.

GAO, Z.; see CHEN, S. T.

GLASBY, S. P., NIEMEYER, A. C. and POPIEL, T.; On the second-largest Sylow subgroup of a finite simple group of Lie type 
GORDILLO-MERINO, A.; see CABELLO SÁNCHEZ, J. 121

GOYAL, M.; An analogue of Euler's identity and split perfect partitions 353

GUO, H.; Positive scalar curvature and Callias-type index theorems for proper actions

GUO, X.; see MENG, H.

GÜRER, S. and IGLESIAS-ZEMMOUR, P.; Differential forms on stratified spaces II

HAN, Q.; see WANG, Q.

HASAN, B. A.; A study on numerical modelling of vector-borne diseases $\quad 523$

HIRSCHHORN, M. D. and SELLERS, J. A.; Parity results for partitions wherein each part appears an odd number of times

HU, B., HUANG, J. and SKIBA, A. N.; On $\sigma$-quasinormal subgroups of finite groups

HU, P.; see WANG, Q.

250

HU, Y.-J.; see WANG, Y.-J.

HUANG, J.; see HU, B. 413

HUANG, Z.; Metrics and special Kähler geometry on the moduli spaces of Higgs bundles and Hitchin systems

IGLESIAS-ZEMMOUR, P.; see GÜRER, S.

340

311

JAMES, T., KLAVŽAR, S. and VIJAYAKUMAR, A.; The domination game on split graphs

JI, C.-G.; see WANG, Y.-J.

JI, C.-G.; see WANG, Y.-J.

369

KARAPINAR, E.; see KOSTIĆ, A.

497

KLAVŽAR, S.; see JAMES, T.

KOSTIĆ, A., KARAPINAR, E. and RAKOČEVIĆ, V.; Best proximity points and fixed points with $R$-functions in the framework of $w$-distances

KOSZ, D.; Dichotomy property for maximal operators in a nondoubling setting

KUMAR, V. and MANCE, B.; On the transcendence of certain real numbers

LI, L.; On maximally Frobenius destabilised vector bundles 195

LI, L. and PONNUSAMY, S.; Note on the convolution of harmonic mappings 421

LIN, S.; see TANG, Z. $\quad 302$

LIU, F.; see LIU, H. $\quad 219$

LIU, H., LIU, F. and WU, H.; The unique continuation property of $p$-harmonic $\begin{array}{ll}\text { functions on the Heisenberg group } & 219\end{array}$

LIU, J.-C. and WANG, C.; Congruences for the ( $p-1)$ th Apéry number 362

$\begin{array}{ll}\text { LIU, Y.; Projective characters with prime power degrees } & 78\end{array}$

LIU, Y.; Existence and blow-up of solutions to a parabolic equation with nonstandard growth conditions

LO, C.-O. and LOH, A. W.-K.; Compact weighted composition operators on $H^{p}$-spaces

LOH, A. W.-K.; see LO, C.-O. 
LOU, B.; see YUAN, L.

LUCA, F. and RIFFAUT, A.; Linear independence of powers of singular moduli of degree three

MA, W.-X. and CHEN, Y.-G.; Representation functions on abelian groups

MANCE, B.; see KUMAR, V.

MARTINI, H.; see BALESTRO, V.

MASTROSTEFANO, D. and SANNA, C.; On numbers $n$ with polynomial image coprime with the $n$th term of a linear recurrence

MATZKE, R.; see BAJNOK, B.

MENG, H. and GUO, X.; Overgroups of weak second maximal subgroups

MOHAMMADINEJAD, H. M.; see ASSADI, A.

MOORS, W. B. and TAN, N. Ö.; Dual differentiation spaces

MOSLEHIAN, M. S., ZAMANI, A. and WÓJCIK, P.; Approximately angle preserving mappings

NASSERDDINE, W.; A compact qualitative uncertainty principle for some nonunimodular groups

NIEMEYER, A. C.; see GLASBY, S. P.

PAŃKOWSKI, Ł.; see DUDEK, A. W.

PATERNAIN, M.; Contractible periodic orbits of Lagrangian systems

PHAM, H. T. T.; Parameter estimation for stage-duration models

PHAM, H. T. T.; Joint models for nonlinear longitudinal and time-to-event data using penalised splines

PONNUSAMY, S.; see LI, L.

POPIEL, T.; see GLASBY, S. P.

RAKOČEVIĆ, V.; see KOSTIĆ, A.

REN, D.; Optimal stopping for the last exit time

RIFFAUT, A.; see LUCA, F.

ROY, B.; see CHATTOPADHYAY, J.

RUSSO, A.; see BRESCIA, M.

ŞAHIN, M. and ŞAHIN, N.; Betti numbers for certain Cohen-Macaulay tangent cones

ŞAHIN, N.; see ŞAHİN, M.

SALAME, K.; Amenable semigroups of nonlinear operators in uniformly convex Banach spaces

SANKI, B.; Embedding of metric graphs on hyperbolic surfaces

SANNA, C.; see MASTROSTEFANO, D.

SCHARASCHKIN, V.; see DUDEK, A. W.

SELLERS, J. A.; see HIRSCHHORN, M. D.

SHI, G.; see YAN, J.

SHOMBERG, J. L.; Global existence of weak solutions for strongly damped wave equations with nonlinear boundary conditions and balanced potentials SHPARLINSKI, I. E.; On finding solutions to exponential congruences 
SKIBA, A. N.; see HU, B. 413

TAN, N. Ö.; see MOORS, W. B. $\quad 467$

TANG, M.; see CHEN, S.-Q. $\quad 15$

TANG, Z. and LIN, S.; On generalised metrisability and cardinal invariants in quasitopological groups

302

THANGADURAI, R.; see CHATTOPADHYAY, J. 177

THOMAS, D. K.; see ALLU, V. $\quad 89$

TOGBÉ, A.; see ZHANG, Z.

TUNESKI, N.; see ALLU, V. $\quad 89$

VEENA SANGEETHA, M.; Geometric and fixed point properties in products of normed spaces 262

VIJAYAKUMAR, A.; see JAMES, T. 327

WANG, C.; see LIU, J.-C. 362

WANG, Q., HAN, Q. and HU, P.; Quantitative properties of meromorphic solutions to some differential-difference equations 250

WANG, Y.-J. and JI, C.-G.; A new Menon's identity from group actions 369

WANG, Y.-J., HU, Y.-J. and JI, C.-G.; Ideal chains in residually finite Dedekind domains $\quad 56$

WÓJCIK, P.; see MOSLEHIAN, M. S.

WRIGHT, T.; Factors of Carmichael numbers and an even weaker $k$-tuples conjecture 376

WU, H.; see LIU, H. 219

YAN, J. and SHI, G.; Multiplicities of eigenvalues of the diffusion operator with random jumps from the boundary 101

YAN, X.-H.; On partitions of nonnegative integers and representation functions 385

YANG, Q.-H.; see CHEN, S.-Q. $\quad 15$

YANG, Y. L.; Positive centre sets of convex curves and a Bonnesen type inequality 293

YUAN, L. and LOU, B.; Entire solutions of a curvature flow in an undulating cylinder

ZAMANI, A.; see MOSLEHIAN, M. S.

ZHANG, Z. and TOGBÉ, A.; Perfect powers that are sums of two powers of Fibonacci numbers 


\section{INFORMATION FOR AUTHORS}

The Bulletin of the Australian Mathematical Society aims at quick publication of original research in all branches of mathematics. To ensure speedy publication, only articles which are sufficiently well presented, able to be published without revision, and which are judged by the Editor (often in consultation with an Associate Editor) to be competitive are refereed. This policy is in the interests of authors, as a quick rejection is better than a slow rejection. The Bulletin receives more than five times the material that can be published, therefore there are many commendable papers not accepted. Editorial decisions on acceptance or otherwise are taken quickly, normally within a month of receipt of the paper. Papers are accepted only after peer review.

Manuscripts are accepted for review with the understanding that the same work is not concurrently submitted elsewhere. For a paper to be acceptable for publication, not only should it contain new and interesting results, but also

(i) the exposition should be clear and attractive, and

(ii) the manuscript should be in publishable form, without revision.

Further information regarding these requirements may be found through our website www.austms.org.au/Bulletin. Authors are asked to avoid, as far as possible, the use of mathematical symbols in the title.

Articles should be prepared in $\mathrm{ET}_{\mathrm{E}} \mathrm{X}$ using $\mathcal{A}_{\mathcal{M}} \mathcal{S}$-LTEX packages and submitted as a PDF file via our journal management system, at www.austms.org.au/Publications/Submissions/BAustMS. This permits authors to track their papers through the editorial process. Recent versions of $\mathrm{T}_{\mathrm{E}} \mathrm{X}$ are able to produce PDF files directly. A LTTEX class file for the Bulletin can be downloaded from the website. Authors who need assistance may email the secretary of the Bulletin at editor@bulletin.austms.org.au.

Authors are advised to keep copies of all files of the submitted article; the Bulletin will not accept responsibility for any loss.

\section{EDITORIAL POLICY}

1. References. Arrange references alphabetically (by surname of the first author) and cite them numerically in the text. Ensure the accuracy of the references: authors' names should appear as in the work quoted. Include in the list of references only those works cited, and avoid citing works which are in preparation or submitted. Where the work cited is not readily accessible (for example, a preprint) a copy of the article should be included with your submission.

\section{Abstracts.}

1. Each paper must include an abstract of not more than 150 words, which should contain a brief but informative summary of the contents of the paper, but no inessential details.

2. The abstract should be self-contained, but may refer to the title.

3. Specific references (by number) to a section, proposition, equation or bibliographical item should be avoided.

3. Subject Classification and Key Words. Authors should include a few key words and phrases and one or more classification numbers, following the American Mathematical Society 2010 Mathematics Subject Classification for all codes. Details of this scheme can be found on the web at www.ams.org/msc.

4. Abstracts of PhD Theses. The Bulletin endeavours to publish abstracts of all accepted Australasian $\mathrm{PhD}$ theses in mathematics. One restriction, however, is that the abstract must be received by the Editor within six months of the degree being approved.

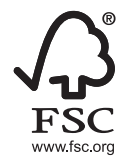

This journal issue has been printed on FSC-certified paper and cover board. FSC is an independent, non-governmental, not-for-profit organisation established to promote the responsible management of the world's forests. Please see www.fsc.org for information. 


\section{Table of Contents}

An analogue of Euler's identity and split perfect partitions

Goyal, $M$.

Congruences for the $(p-1)$ th Apéry number

Liu, 7.-C. \& Wang, C.

A new Menon's identity from group actions

Wang, Y.-7. E. Fi, C.-G.

Factors of Carmichael numbers and an even weaker $\boldsymbol{k}$-tuples conjecture

Wright, T.

On partitions of nonnegative integers and representation functions

Yan, X.-H

On finding solutions to exponential congruences

Shparlinski, I. E.

On the transcendence of certain real numbers

Kumar, V. \& Mance, B.

Finite unitary rings in which all Sylow subgroups of the group of units are cyclic

Amiri, M. E Ariannejad, $M$.

On $\sigma$-quasinormal subgroups of finite groups

Hu, B., Huang, 7. E Skiba, A. N.

Note on the convolution of harmonic mappings

Li, L. \& Ponnusamy, S.

Global existence of weak solutions for strongly damped wave equations with nonlinear boundary conditions and balanced potentials

Shomberg, 7. L.

Contractible periodic orbits of Lagrangian systems

Paternain, $M$.

Dichotomy property for maximal operators in a nondoubling setting

Kosz, D

Dual differentiation spaces

Moors, W. B. \& Tan, N. Ö.

Compact weighted composition operators on $\boldsymbol{H}^{p}$-spaces

Lo, C.-O. Eं Loh, A. W.-K

Approximately angle preserving mappings

Moslehian, M. S., Zamani, A. \& Wójcik, $P$.

Best proximity points and fixed points with $\boldsymbol{R}$-functions in the framework of $\boldsymbol{w}$-distances Kostić, A., Karapinar, E. \& Rakočević, V.

Embedding of metric graphs on hyperbolic surfaces

Sanki, $B$.

Abstracts of PhD Theses

The classification of categories generated by an object of small dimension

Edie-Michell, $C$.

A study on numerical modelling of vector-borne diseases

Hasan, B. A.

Author Index for Volume 99 